\title{
Trichomoniasis and associated co-infections of the genital tract among pregnant women presenting at two hospitals in Ghana
}

\author{
Richard H. Asmah ${ }^{1 \dagger}$, Harriet N. A. Blankson ${ }^{1 *+}$, Kekeli A. Seanefu', Noah Obeng-Nkrumah',
} Georgina Awuah-Mensah', Momodou Cham² and Patrick F. Ayeh-Kumi ${ }^{3}$

\begin{abstract}
Background: Trichomonas vaginalis (TV) infection is the most prevalent non-viral sexually transmitted pathogen worldwide. Among pregnant women, the infection may cause adverse birth outcomes such as premature rupture of membranes and premature labour. In view of the paucity of information relating to TV among Ghanaian pregnant women, this study investigated its prevalence and associated co-infections among pregnant women.

Methods: High vaginal swabs were obtained from 99 pregnant women using sterile cotton swab sticks. Wet preparation, Grams staining, culturing, coagulase and sensitivity testing were carried out to determine the presence of $T V$ and associated microorganisms.

Results: The prevalence of TV among the pregnant women was found to be $20.2 \%(n=20)$. Concurring with Trichomoniasis, $75 \%(n=15)$ of participants had other infections such as Candida with prevalence of 53\% $(n=8)$, Proteus infection - 20\% ( $n=3)$, Streptococcus infection - 13\% $(n=2)$ and other GNRs and Gonococci having 7\% each $(n=1)$. Moreover, there was $86.9 \%(n=86)$ prevalence of Staphylococcus spp. among study participants. There was statistically significant correlation between TV and Gonococci infection at a correlation co-efficient of $0.107(P<0.05)$ as well as significant correlation between TV and Proteus spp. at a correlation co-efficient of $0.189(P<0.05)$. TV infection was high (60\%) among the most sexually active age group (19 to $29 \mathrm{yrs}$ ).
\end{abstract}

Conclusion: There was $20.2 \%$ prevalence of $T V$ among the pregnant women presenting at the hospitals, with Gonococci and Proteus infections being statistically significant associated infections.

Keywords: Trichomonas vaginalis, Coinfections, Gonococci, Proteus, Pregnant women

\section{Background}

Trichomonas vaginalis (TV) infection is the most prevalent non-viral Sexually Transmitted Infection (STI) globally; the World Health Organization (WHO) estimated prevalence from 170 million to 190 million cases worldwide yearly [1]. Sutton et al. (2007) reported a 13.3\% prevalence in African American women with $85 \%$ of women found to have trichomoniasis presenting

\footnotetext{
*Correspondence: habbey@ug.edu.gh

${ }^{\dagger}$ Equal contributors

${ }^{1}$ Department of Medical Laboratory Sciences, School of Biomedical and Allied Health Sciences, College of Health Sciences, University of Ghana, Accra, Ghana

Full list of author information is available at the end of the article
}

with no symptoms [2]. Although rate of STIs are decreasing, trichomoniasis however remains a very common infection [3].

Trichomoniasis infection has been associated with vaginitis, cervicitis, urethritis, pelvic inflammatory disease (PID), adverse birth outcomes [4] as well as increased transmission of HIV [5]. Though the disease can be easily treated and is preventable, it is often asymptomatic, and its acquisition and transmission are often accompanied by other serious STIs [6]. The fact that the infection may be asymptomatic makes it not only a personal problem, but also a public health challenge. 
Poor sexual practices such as multiple partners and bad hygiene regarding reproductive organs increase incidence of vaginal trichomoniasis. Individuals of low socioeconomic status as well as those infected with HIV and Hepatitis B Virus are part of the at risk group [7].

A report by the JSI Research and Training Institute, Inc. (2013) indicates that populations of the urban centres in Ghana are better educated, have better access to health facilities are more exposed to health control messages than those in the rural communities [8]. Though studies have been conducted to ascertain the prevalence of $T V$ infection in many countries, not much has not been recorded in Ghana especially on pregnant women. The study was thus conducted to determine the prevalence of this infection and any other genital infections among pregnant women presenting at two (2) major hospitals at Sogakope, a town in the Volta Region of Ghana.

\section{Methods}

\section{Study area}

This study was conducted in Sogakope at the Saint Comboni and the South Tongu District hospitals. Sogakope is a town in the South Tongu District, a district in the Volta Region of Ghana. It has a population of 104,194 .

\section{Study design and sampling method}

This research was designed as a facility-based crosssectional study and it was conducted from April to June, 2016. Simple Random sampling was used.

\section{Study participants, inclusion and exclusion criteria}

The participants of the study comprised pregnant women who had been received for antenatal care as well as those visiting the laboratory for routine urine examination at the Saint Comboni and the South Tongu District hospitals in Sogakope. Pregnant women in any of the trimesters who consented were allowed to participate in the study irrespective of age. Only participants who were permanent residents or have lived at Sogakope for at least 6 months were included in the research. Those excluded from the study were pregnant women who are on antibiotics and vaginal medications and pregnant women who had sex three days prior to data collection.

\section{Data collection procedure}

Sociodemographic and medical history data were collected using structured questionnaires by engaging in a face to face interview with each consenting participant. Two sterile cotton tipped swab sticks, one after the other were inserted at least $2.5 \mathrm{~cm}$ ( 1 in.) into the vagina of each pregnant woman and turned in the inner wall while counting to 10 to collect vaginal fluid (secretions) onto the swab by a clinician. Informed consent was obtained from all participants (consent from parent or legal guardian was obtained from those below the age of 16).

\section{Laboratory analysis and diagnosis}

One of the swabs taken was immediately washed in a drop of physiological saline on a clean grease-free labelled frosted end glass slide and cover slipped. Slides were scanned with $\times 10$ objective and examined with $\times 40$ objective using a light microscope. The second swab stick was stored in swab tubes containing Amies medium and transported to the microbiology lab of the SBAHS for culture and gram staining to identify any bacterial infections.

The procedure and principle for gram staining employed in the study as well as the agar preparation protocols involved were adopted from the book: District Laboratory Practice in Tropical Countries (Part II) by Cheesbrough (2005).

Prepared chocolate agar media were dried in an oven, labelled and made ready for inoculation. The swabs (in the transport medium) were used to make a pool each on a plate and subsequently streaked with a sterile inoculating loop after which they were incubated for 18 to $24 \mathrm{~h}$.

\section{Data analysis}

Data were entered into Statistical Package for Social Sciences (SPSS) version 20.0 and analyzed alongside with Microsoft excel 2013. Descriptive statistics such as bar and pie charts were used as well as Pearson correlation were used in describing the data. Data entered in the computer were locked with a password while other materials in hard copy were taken to the SBAHS archives.

\section{Results}

A total of 99 pregnant women consented to participate in the study. They were placed into 3 groups. Those ages 18 years and below were (23), those between the ages 19 to 29 (42) and then those 30 years and above (34).

\section{Genital infections among study participants}

The prevalence of $T V$ was found to be $20.2 \%$ which corresponds to twenty (20) of the overall participants in the research study (Fig. 1).

Several other infections were identified among the study participants. These infections and their frequencies presented in Fig. 3 show Candida to be the highest infection $(n=35 ; 35.4 \%)$ recorded.

It is noteworthy that 86 out of the 99 participants (86.9\%) were positive for Staphylococcus spp. Similarly, out of the positive $T V$ cases $(n=20)$, fifteen (15) were Staph positive. Species identification of the Staphs 


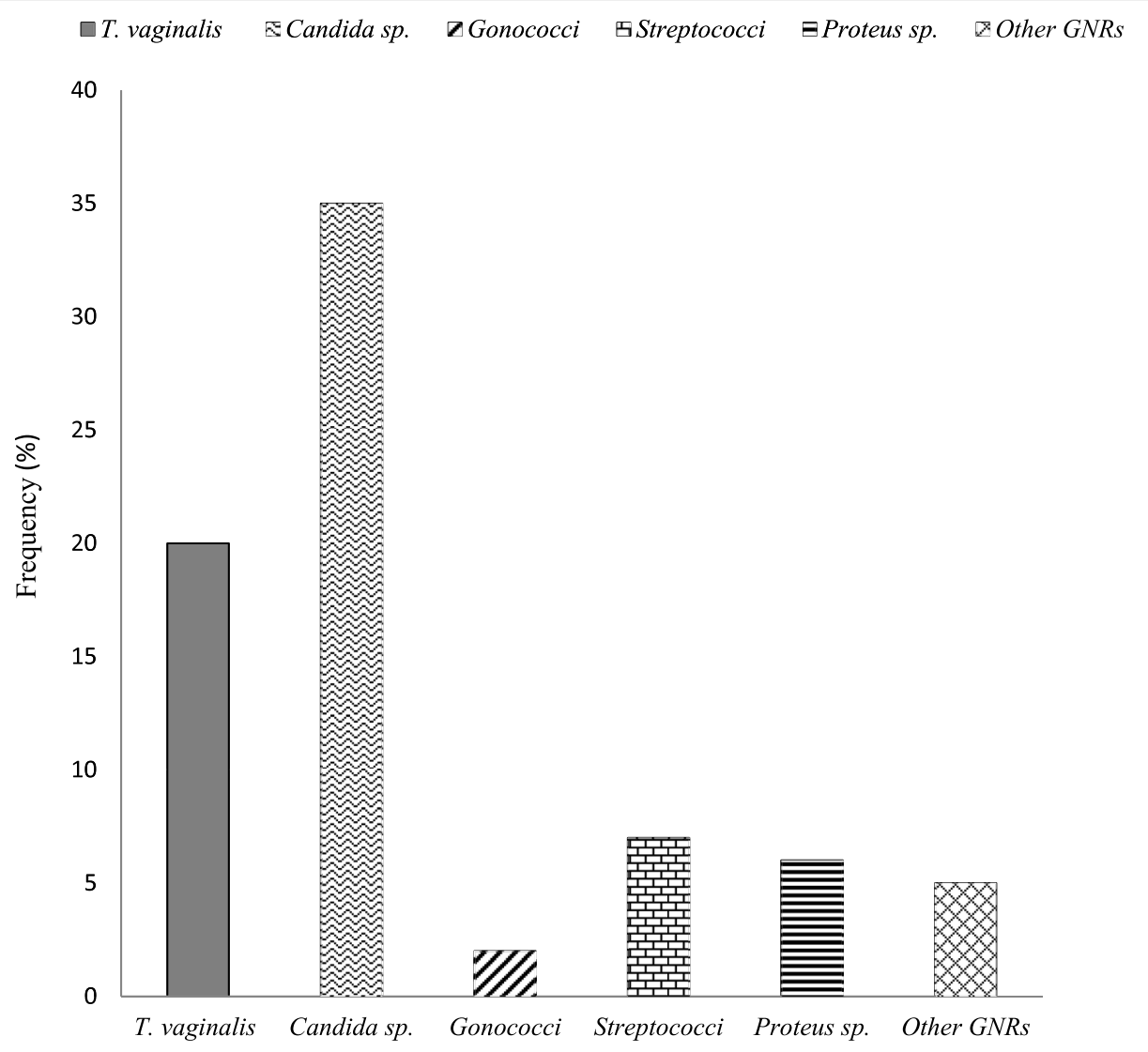

Fig. 1 Genital Infections among Study Participants, GNRs = Gram Negative Rods

among participants with $T$. vaginalis indicated however that $73.4 \%(n=11)$ are $S$. epidermidis, a normal flora of the skin as shown in Fig. 2.

Table 1 reveals the bacteria identification criteria using gram staining and biochemical (coagulase) and Sensitivity tests using Novobiocin antibiotic.

\section{Trichomoniasis with other genital infections}

One major objective of the study was to identify genital infections that co-existed with $T V$. Figure 3 below reveals that Candida (53\%) co-existed more with $T$. vaginalis. Other infections recorded were as low as $7 \%$ (other GNRs).

\section{Association between TV and other genital infections}

Statistical correlation was done for four (4) organisms (Proteus, Strep, Candida, and Gonococci) that were found to co-exist with $T V$. Tables 2 and 3 show the findings.

The analyses showed that $T V$ and Candida had a positive correlation that was statistically significant (0.049, $p=0.05$ ), as shown in Table 2 (confidence interval 99\%). There was also a statistically significant correlation between $T V$ and Gonococci infection at a correlation co-efficient of $0.107(P$-value $=0.05)$.

The correlation matrix (Table 3 ) also points out a significant correlation between $T V$ and Proteus spp. at a correlation co-efficient of $0.189 \quad(P$-value $=0.05)$. Similarly, at a correlation co-efficient of 0.057 ( $P$-value $=0.05$ ), there was a statistically significant relation between Strep spp. and $T V$ infection at a significant level of 0.01 (99\% confidence interval).

\section{Age association with $T V$ infection}

The data also showed an association of $T V$ infection with age based on the three groups formed $(\leq 18,19-$ 29 years, $30 \geq$ ). The findings captured in Table 4 reveal that the age group 19 to 29 years has the highest frequency $(60 \%)$ of $T V$ infection.

\section{Discussion}

Trichomoniasis is a common infection of the genital tract caused by a flagellated protozoon, Trichomonas vaginalis and considered chiefly as sexually transmitted since non-veneral transmission has not yet been well documented or published [9] It may be asymptomatic 


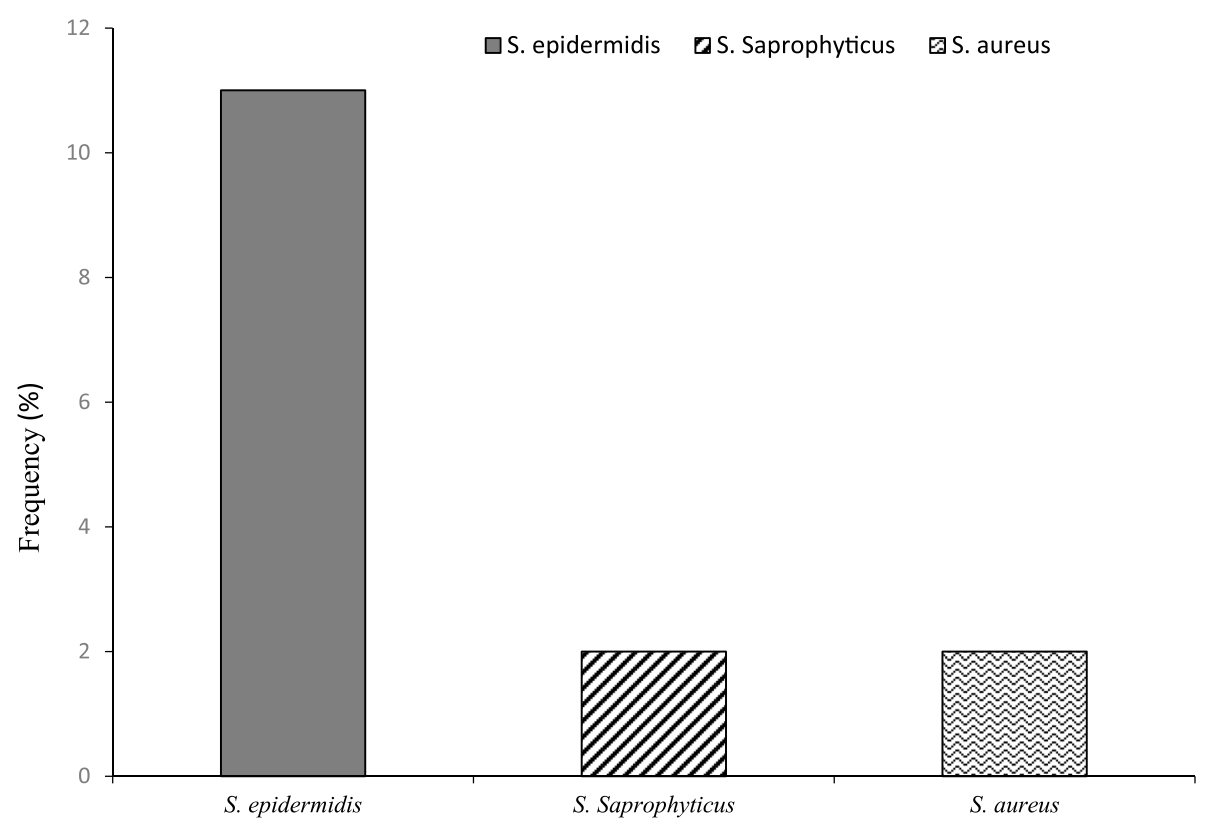

Fig. 2 Distribution of Staphylococcus species Among TV Positives

[5] in a large proportion of infected women though it elicits an acute inflammatory response resulting in vaginal discharge, vaginal itching or irritation and a frothy grey to green- yellow discharge, vaginal malodor and dysuria. $T V$ may lead to premature rupture of membranes, premature labour and low birth weight [10-12] which makes the infection a serious health concern among pregnant women.

\section{Prevalence of $T$. vaginalis among participants}

Studies have been conducted to ascertain the prevalence of $T V$ infection in many countries, however much has not been recorded in Ghana especially on pregnant women. Results from this study indicated that the prevalence of $T V$ among pregnant women presenting at the South Tongu District and St. Comboni Hospitals in Sogakope is $20.2 \%$.

It was also observed that there were several other genital infections among the study participants, namely Candida spp. (35.4\%) Streptococcus spp. (7.1\%) Gonococcus spp. (2.0\%). Proteus spp. (6.1\%) and other GNRs (5.1\%).

The above notwithstanding, there was $86.9 \%(n=86)$ prevalence of Staphylococcus spp. among the study participants. Further investigation was done especially on the positive $T V$ cases that were also Staph positive $(n=15)$. It was revealed that $73.4 \%(n=11)$ are $S$. epidermidis as shown in Fig. 2 with the rest being S. aureus $(n=2)$ and $S$. saprophyticus $(n=2)$. S. epidermidis has been regarded as typically normal flora of the skin and less commonly as mucosal flora that is non-pathogenic, controlling growth of the more pathogenic counterpart S. aureus [13]. Their isolation in the study could be due to contamination from labia majora of the vagina during sample collection. The bacteria S. epidermidis have recently been associated with nosocomial infections, where the organism is responsible for about $22 \%$ of bloodstream infections. It does not necessarily attack hosts by producing toxins but it may have

Table 1 Bacteria identified based on biochemical reactions

\begin{tabular}{lllll}
\hline Gram Stain Reaction & Coagulase Test & Swarming on Chocolate Media & Susceptibility to Novobiocin & Bacteria identified \\
\hline Gram negative rod & NA & Positive & NA & Proteus sp \\
Gram negative rod & NA & NA & NA & Other GN Rods \\
Gram positive cocci in clusters & Positive & NA & NA & Staphylococcus aureus \\
Gram positive cocci in clusters & Negative & NA & Resistant & Staphylococcus saprophyticus \\
Gram positive cocci in clusters & Negative & NA & Susceptible & Staphylococcus epidermidis \\
Gram positive cocci in chains & NA & NA & NA & Streptococcus sp. \\
\hline
\end{tabular}




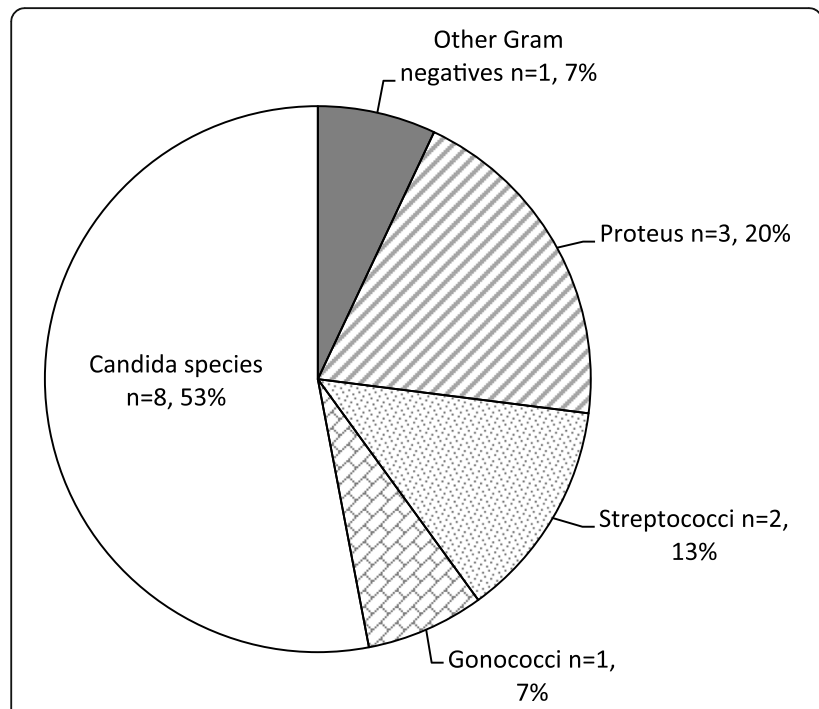

Fig. 3 Co-infections with TV

immune evasion mechanisms which allows its proliferation [14]. Similarly, S. saprophyticus is a normal flora of the female genital tract and perineum and can cause 10$20 \%$ of urinary tract infections if displaced from the normal flora of the vagina and perineum into the urethra [15]. Care must hence be taken in such instances of its infection even though it does not demand much attention.

Among others, one mode of transmission of $S$. aureus is through direct contact with objects that are contaminated by the bacteria. It is opportunistic in such a way that it takes advantage of a breach in skin or other entry sites to become pathogenic [16]. Hence, infection of the female genital tract by $S$. aureus hence should be of great concern and all women need to be educated against it.

\section{Trichomoniasis with other genital infections}

The prevalence of $T V$ among the pregnant women who presented at the South Tongu District and St. Comboni
Hospitals in Sogakope during the period of study was found to be $20.2 \% \quad(n=20)$. Co-ocurring with Trichomoniasis, fifteen (15) participants had infections such as Gonorrhea, Candida spp., Streptococci spp., Proteus spp. and other Gram negative rods as shown in Fig. 3. Candida infection tops the list with 53\% $(n=8)$, followed by Proteus infection with $20 \%(n=3)$, Streptococcus infection with $13 \%(n=2)$ and other GNRs and Gonococci with $7 \%$ each $(n=1)$.

Yeast infections are a common type of vaginal infections and they are especially common in pregnant women as they become immunocompromised during that period [17]. It was therefore not surprising to find that Candida spp. was the leading infection that coexisted with $T V$ among the study participants. Proteus species as well as other GNRs such as Klebsiella spp., E. coli, etc. are implicated as serious causes of infection in humans most commonly found urinary tract [18]. Urinary tract infections are the most common clinical manifestations of Proteus infections [19]. This could be due to the proximity of the female genitalia to the anal orifice which may encourage contamination/infection of the vagina with Enterobacteriaceae (GNRs) under poor hygienic conditions. There is therefore a need for women especially those in less health endowed communities and rural areas to be educated on the relevance of personal hygiene and the appropriate cleaning of the private part (anus and vagina).

According to the Gonorrhea CDC Fact Sheet (2014), "anyone who is sexually active can get gonorrhea" as STD. It was further stated that "a pregnant woman with gonorrhea can give the infection to her baby during childbirth". The complications that come along with this infection such as neonatal conjunctivitis (ophthalmia neonatorum) should be given much attention in order to ameliorate or reduce the rate of incidence. Aside abstinence from all forms of sex, the fact sheet advices a mutually monogamous relationship with a known gonorrhea negative individual or protection with the use of condom [20].

Table 2 Correlation between TV, Candida and Gonoccoci infection

\begin{tabular}{|c|c|c|c|c|}
\hline & & Candida infection & Gonococci infection & T. vaginalis infection \\
\hline \multirow[t]{3}{*}{ Candida infection } & Pearson Correlation & 1 & -.106 & $.049^{b}$ \\
\hline & Sig. (2-tailed) & & .296 & .631 \\
\hline & $\mathrm{N}$ & 99 & 99 & 99 \\
\hline \multirow[t]{3}{*}{ Gonococci infection } & Pearson Correlation & -.106 & 1 & $.107^{\mathrm{a}}$ \\
\hline & Sig. (2-tailed) & .296 & & .294 \\
\hline & $\mathrm{N}$ & 99 & 99 & 99 \\
\hline \multirow[t]{3}{*}{ TV infection } & Pearson Correlation & $.049^{b}$ & $.107^{\mathrm{a}}$ & 1 \\
\hline & Sig. (2-tailed) & .631 & .294 & \\
\hline & N & 99 & 99 & 99 \\
\hline
\end{tabular}

a Correlation is significant at the 0.05 level (2-tailed)

${ }^{\mathrm{b} C}$ Correlation is significant at the 0.01 level (2-tailed) 
Table 3 Correlations between TV, Strep and Proteus

\begin{tabular}{|c|c|c|c|c|}
\hline & & Streptococci species & Proteus species & Trichomonas vaginalis infection \\
\hline \multirow[t]{3}{*}{ Streptococci species } & Pearson Correlation & 1 & -.070 & $.057^{\mathrm{b}}$ \\
\hline & Sig. (2-tailed) & & .491 & .572 \\
\hline & N & 99 & 99 & 99 \\
\hline \multirow[t]{3}{*}{ Proteus species } & Pearson Correlation & -.070 & 1 & $.189^{\mathrm{a}}$ \\
\hline & Sig. (2-tailed) & .491 & & .062 \\
\hline & N & 99 & 99 & 99 \\
\hline \multirow[t]{3}{*}{ Trichomonas vaginalis infection } & Pearson Correlation & $.057^{\mathrm{b}}$ & $.189^{\mathrm{a}}$ & 1 \\
\hline & Sig. (2-tailed) & .572 & .062 & \\
\hline & $\mathrm{N}$ & 99 & 99 & 99 \\
\hline
\end{tabular}

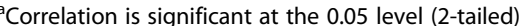

${ }^{b}$ Correlation is significant at the 0.01 level (2-tailed)

\section{Correlation between TV infection and its associated infections}

Of the diverse organisms that were found to co-exist with $T V$, there was analysis to identify any significant association or correlation as revealed in Tables 2 and 3.

Trichomonas vaginalis and Candida had a positive correlation that was statistically significant $(0.049, p=$ 0.05) as shown in Table 2 (confidence interval 99\%). Though this correlation is not significant as per the 95\% confidence interval set, the correlation revealed a statistically significant co-efficient at the 99\% confidence interval. This suggests that there is an association between $T V$ infection and Candida infection though not a very strong one.

There was as well statistically significant correlation between $T V$ and Gonococci infection at correlation co-efficient of 0.107 ( $P$-value $=0.05)$ (Table 2). This portrays a strong relationship between the two infections. That one out of the two positive Gonococci cases encountered among the 99 participants was among the only 20 positive $T V$ cases indicates that there is indeed a strong correlation between $T V$ infection and Gonococci infection. Better still, there is a high probability for the two infections to co-exist since they are both STDs.

Additionally, the correlation matrix (Table 3) also points out a significant correlation between $T V$ and Proteus spp. at a correlation co-efficient of 0.189 ( $P$ -

Table 4 Relationship between Age and TV infection among Participants

\begin{tabular}{llll}
\hline Age & Frequency & Percent & Cumulative Percent (\%) \\
\hline 18 yrs. and below & 3 & 15.0 & 15.0 \\
19 to 29 yrs & 12 & 60.0 & 75.0 \\
30 yrs. and above & 5 & 25.0 & 100.0 \\
Total & 20 & 100.0 & \\
\hline
\end{tabular}

value $=0.05)$. Similarly, at a correlation co-efficient of 0.057 ( $P$-value $=0.05)$, there was a statistically significant relation between Strep spp. and $T V$ infection at a significant level of 0.01 (99\% confidence interval). Per Edwards et al. (2016), "the pathology of trichomoniasis results from damage to epithelia, caused by a variety of processes during infection and that recent work has highlighted the complex interactions between parasite and host, commensal microbiome and accompanying symbionts" [21]. This explains why infections such as those caused by Strep spp. and Proteus spp. could be associated with $T V$. For example, in the condition of $T V$ infection, the epithelia of the vagina may be disturbed alongside the normal flora of the site such as lactobacilli. Since these bacteria are the main organisms responsible for the normal $\mathrm{pH}$ of the vagina, their disturbance could pose a great threat where other opportunistic infections may set in. Similarly, co-infections may result in one becoming immunocompromised, less productive and incurring of much loss in the treatment of infections.

\section{Age relationship with $T V$}

Participants of age group 19 to 29 years had the highest frequency of infection (60\%). Those who were 30 and above had a $25 \%$ frequency while those who were 18 and below had the lowest frequency, $15 \%$. The results correspond to the fact that sexually active individuals fall within the highest age group frequency and hence can be regarded as a sound reason for such results. According to the World Health Organization (WHO), TV infection is a sensitive marker of high-risk sexual behavior [22]. The findings also agree with a research by Nazari et al. (2015) conducted in Iran to identify the prevalence of $T V$ among women. They found that infection rate was lower in the less than 20 yr. old groups (5.6\%) and higher in the sexually active year groups $(20 \mathrm{yr}$. to 40 yrs. $-62 \%)$ [12]. 


\section{Conclusion}

$T V$, mostly an asymptomatic sexually transmitted infection, is predominantly evident in sexually active individuals and pregnant women fall into this category. The immunocompromising state of a pregnant woman is a contributing factor for the manifestation of infections which can have adverse effects on the mother and the unborn child. It is noteworthy that most $T V$ infections among pregnant women are usually co-infections with other genital tract infections and their associated complications.

The rampant nature of the condition in recent times, despite all other strategies to curb it, indicates that it is still a serious public health concern that needs to be addressed. Pregnant women should particularly be encouraged to have themselves screened for the presence of the infection. Sexually active individuals ought to ensure faithfulness to their partners or where in doubt, maximize the use of protection in sexual intercourse to protect themselves against infection.

\section{Abbreviations \\ BV: Bacterial Vaginosis; DNA: Deoxyribonucleic Acid; GNRs: Gram Negative Rods; HBV: Hepatitis B Virus; HIV: Human Immunodeficiency Virus; NAAT: Nucleic Acid Amplification Technique; pH: Power of hydrogen; PID: Pelvic Inflammatory Disease; RTIs: Reproductive Tract Infections; SBAHS: School of Biomedical and Allied Health Sciences; St:: Saint; STI: Sexually Transmitted Infection; TV: Trichomonas vaginalis; US CDC: United State Centre for Disease Control; USAID: United States Aid for International Development; WHO: World Health Organization; Yrs: Years}

\section{Acknowledgements}

We are grateful to Prof. A.K. Nyarko of School of Pharmacy, College Health Sciences, Mr. Michael Olu Taiwo of SBAHS Microbiology Laboratory and BMS Sampson Kafui Djonor for all their support. Our sincere gratitude to all the Staff in the Laboratories of St. Comboni Hospital and the South Tongu District Hospital, both in Sogakope, the Administrators of these hospitals, as well as all participants in this research work for their cooperation that led to the success of the work.

\section{Funding}

Not applicable.

\section{Availability of data and materials}

The datasets used and/or analysed during the current available from the corresponding author on request.

\section{Authors' contributions}

RHA conceived the study, participated in the design, interpretation and coordination of study and assisted in manuscript drafting. HNB participated in the design interpretation and coordination of study and drafted the manuscript. NONparticipated in design and analysis of study as well as drafting of manuscript. KAS carried out laboratory and statistical analysis and helped in drafting manuscript. GAM participated in design and coordination and drafting of study. MC participated in data collection and manuscript draft. PAK participated in design and coordination of study. All authors read and approved the final manuscript.

\section{Ethics approval and consent to participate}

The study was approved by the Ethical and Protocol Review Committee of School of Biomedical and Allied Health Sciences at the University of Ghana (Ethical identification number SBHAS/10420770/AA/MLS/20115-2016). Confidentiality of all information received from the study was ensured. The purpose of the study was clearly explained to the study subjects and written consent was obtained from each study participant. Confidentiality of the result was kept by coding participant information and specimen.
Consent for publication

Not applicable.

\section{Competing interests}

The authors declare they have no competing interests.

\section{Publisher's Note}

Springer Nature remains neutral with regard to jurisdictional claims in published maps and institutional affiliations.

\section{Author details}

${ }^{1}$ Department of Medical Laboratory Sciences, School of Biomedical and Allied Health Sciences, College of Health Sciences, University of Ghana, Accra, Ghana. ${ }^{2}$ Comboni Catholic Hospital, Sogakope, Ghana. ${ }^{3}$ Department of Microbiology, School of Biomedical and Allied Health Sciences, College of Health Sciences, University of Ghana, Accra, Ghana.

Received: 22 February 2017 Accepted: 30 November 2017

Published online: 13 December 2017

\section{References}

1. Van Der Pol B. Editorial Commentary: Trichomonas vaginalis Infection: The Most Prevalent Nonviral Sexually Transmitted Infection Receives the Least Public Health Attention. Clin. Infect. Dis. [Internet]. 2007;44:23-5. [cited 2017 Jan 25].

2. Sutton M, Sternberg M, Koumans EH, McQuillan G, Berman S, Markowitz L. The Prevalence of Trichomonas vaginalis Infection among Reproductive-Age Women in the United States, 2001-2004. Clin. Infect. Dis. [Internet]. Oxford University Press; 2007 [cited 2017 Jan 25];45:1319-26.

3. Schwebke JR. Update of trichomoniasis. Sex Transm Infect. 2002;78:378-9.

4. Swygard $H$. Trichomoniasis: clinical manifestations, diagnosis and management. Sex Transm Infect [Internet] 2004;80:91-95.

5. Sorvillo F, Smith L, Kerndt P, Ash L. Trichomonas vaginalis, HIV, and AfricanAmericans. Emerg Infect Dis. 2001;7:927-32.

6. Taylor E, Barlow D, Blackwell AL, Phillips I. Gardnerella vaginalis, Anaerobes and Vaginal discharge. Lancet [Internet]. Elsevier; 1982 [cited 2017 Jan 25]; 319:1376-9

7. Rezaeian M, Vatanshenassan M, Rezaie S, Mohebali M, Niromand N, Niyyati $\mathrm{M}$, et al. Prevalence of Trichomonas vaginalis using parasitological methods in Tehran. Iran J Parasitol. 2009:4:43-7.

8. JSI Research \& Training Institute. Report of the Ghana urban malaria study [internet]. Accra; 2013.

9. Cudmore SL, Delgaty KL, Hayward-McClelland SF, Petrin DP, Garber GE. Treatment of infections caused by metronidazole-resistant Trichomonas vaginalis. Clin. Microbiol. Rev. [Internet]. American Society for Microbiology (ASM); 2004 [cited 2017 Jan 25];17:783-93, table of contents.

10. Mielczarek E, Blaszkowska J. Trichomonas vaginalis: pathogenicity and potential role in human reproductive failure. Infection [Internet]. Springer Berlin Heidelberg; 2016 [cited 2017 Jan 26]:44:447-58.

11. Hobbs MM, Lapple DM, Lawing LF, Schwebke JR, Cohen MS, Swygard H, et al. Methods for detection of Trichomonas vaginalis in the male partners of infected women: implications for control of trichomoniasis. J. Clin. Microbiol. [Internet]. American Society for Microbiology (ASM); 2006 [cited 2017 Jan 26]:44:3994-9.

12. Nazari N, Zangeneh M, Moradi F, Bozorgomid A. Prevalence of Trichomoniasis Among Women in Kermanshah, Iran. Iran. Red Crescent Med. J. [Internet]. 2015;17:17-20.

13. Duguid IG, Evans E, Brown MR, Gilbert P. Growth-rate-independent killing by ciprofloxacin of biofilm-derived Staphylococcus epidermidis; evidence for cell-cycle dependency. J. Antimicrob. Chemother. [Internet]. 1992 [cited 2017 Jan 26];30:791-802.

14. Otto M. Staphylococcus epidermidis - the'accidental'pathogen. Nat Rev Microbiol [Internet]. 2009;7:555-67.

15. Widerström M, Wiström J, Sjöstedt A, Monsen T. Coagulase-negative staphylococci: update on the molecular epidemiology and clinical presentation, with a focus on Staphylococcus epidermidis and Staphylococcus saprophyticus. Eur. J. Clin. Microbiol. Infect. Dis. [Internet]. Springer-Verlag; 2012 [cited 2017 Jan 26];31:7-20.

16. Hare R, Thomas CG. The transmission of Staphylococcus aureus. Br Med J. 1956:2:840-4. 
17. García Heredia M, García SD, Copolillo EF, Cora Eliseth M, Barata AD, Vay CA, et al. Prevalence of vaginal candidiasis in pregnant women. Identification of yeasts and susceptibility to antifungal agents. Rev. Argent. Microbiol. [Internet]. 2006 [cited 2017 Jan 26];38:9-12.

18. Ronald A. The etiology of urinary tract infection: traditional and emerging pathogens. Dis Mon. 2003:49:71-82.

19. Chen C-Y, Chen Y-H, Lu P-L, Lin W-R, Chen T-C, Lin C-Y. Proteus Mirabilis urinary tract infection and bacteremia: risk factors, clinical presentation, and outcomes. J. Microbiol. Immunol. Infect. [internet]. Elsevier Taiwan LLC; 2012; 45:228-236.

20. CDC - Centers for Disease Control and Prevention. Gonorhea - CDC Fact Sheet. Cent. Dis. Control Prev. 2014;1-2.

21. Edwards T, Burke P, Smalley H, Hobbs G. Trichomonas vaginalis: Clinical relevance, pathogenicity and diagnosis. Crit. Rev. Microbiol. [Internet]. 2014 [cited 2017 Jan 26];1-12.

22. World Health Organization. Prevalence and incidence of selected sexually transmitted infections: Chlamydia trachomatis, Neisseria gonorrhoeae, syphilis and Trichomonas vaginalis: Methods an results used by WHO to generate 2005 estimates. WHO. 2011;1-38.

\section{Submit your next manuscript to BioMed Central} and we will help you at every step:

- We accept pre-submission inquiries

- Our selector tool helps you to find the most relevant journal

- We provide round the clock customer support

- Convenient online submission

- Thorough peer review

- Inclusion in PubMed and all major indexing services

- Maximum visibility for your research

Submit your manuscript at www.biomedcentral.com/submit 